\title{
Formulation and Evaluation of Sustained Release Sumatriptan Mucoadhesive Intranasal in-Situ Gel
}

\author{
Hussein K. Alkufi *,1 and Hanan J. Kassab ${ }^{* *}$
}

* Department of Clinical and Laboratory Sciences, College of Pharmacy, Thi-Qar University, Thi-Qar, Iraq

** Department of Pharmaceutics, College of Pharmacy, University of Baghdad, Baghdad, Iraq.

\begin{abstract}
Sumatriptan(ST) is a selective agonist at serotonin 5-HTI receptors, as well as 5-HT1B/1D subtypes. It is effective for acute migraine attacks, but has a short half life (about 2 hours) and low oral bioavailability (15\%). The purpose of this study was to develop and optimize nasal mucoadhesive in-situ gel(IG) of ST to enhance nasal residence time for migraine management. Cold method was used to prepare different formulas of ST nasal IG, using thermosensitive polymers (poloxamer 407 alone or with poloxamer 188) with a mucoadhesive polymer hyaluronic acid (HA) which were examined for gelation temperature and gelation time, $\mathrm{pH}$, drug content, gel strength, spreadability, mucoadhesive force determination, viscosity, in-vitro drug release, and the selected formula was subjected to fourier transform infrared (FTIR) compatibility studies, and to ex-vivo permeation study, histological evaluation of the sheep mucosal tissue after ST nasal gel application for 6 hours. The results showed that the formula IG7 prepared from poloxamer 407(19\%), poloxamer188 (4\%) and HA (0.5\%) had an optimum gelation temperature $\left(32.66 \pm 1.52^{\circ} \mathrm{C}\right)$, gel strength $(43.66 \pm 1.52 \mathrm{sec})$, mucoadhesive force $(8067.93 \pm$ 746.45 dyne $\mathrm{cm}^{2}$ ), in-vitro drug release $(95.98 \%)$ over $6 \mathrm{~h}$, ex-vivo permeation study $(89.6 \%)$ during the $6 \mathrm{~h}$. study with no histological or pathological change in the nasal sheep tissue and no interaction between drug and other additives in IG7. Formulation of ST as a nasal insitu gel to avoid first pass metabolism and ease of administration coupled with less frequent and sustained drug release, will enhance patient compliance.
\end{abstract}

Keywords: In-situ gel, poloxamer407, poloxamer188, hyaluronic acid, sumatriptan.

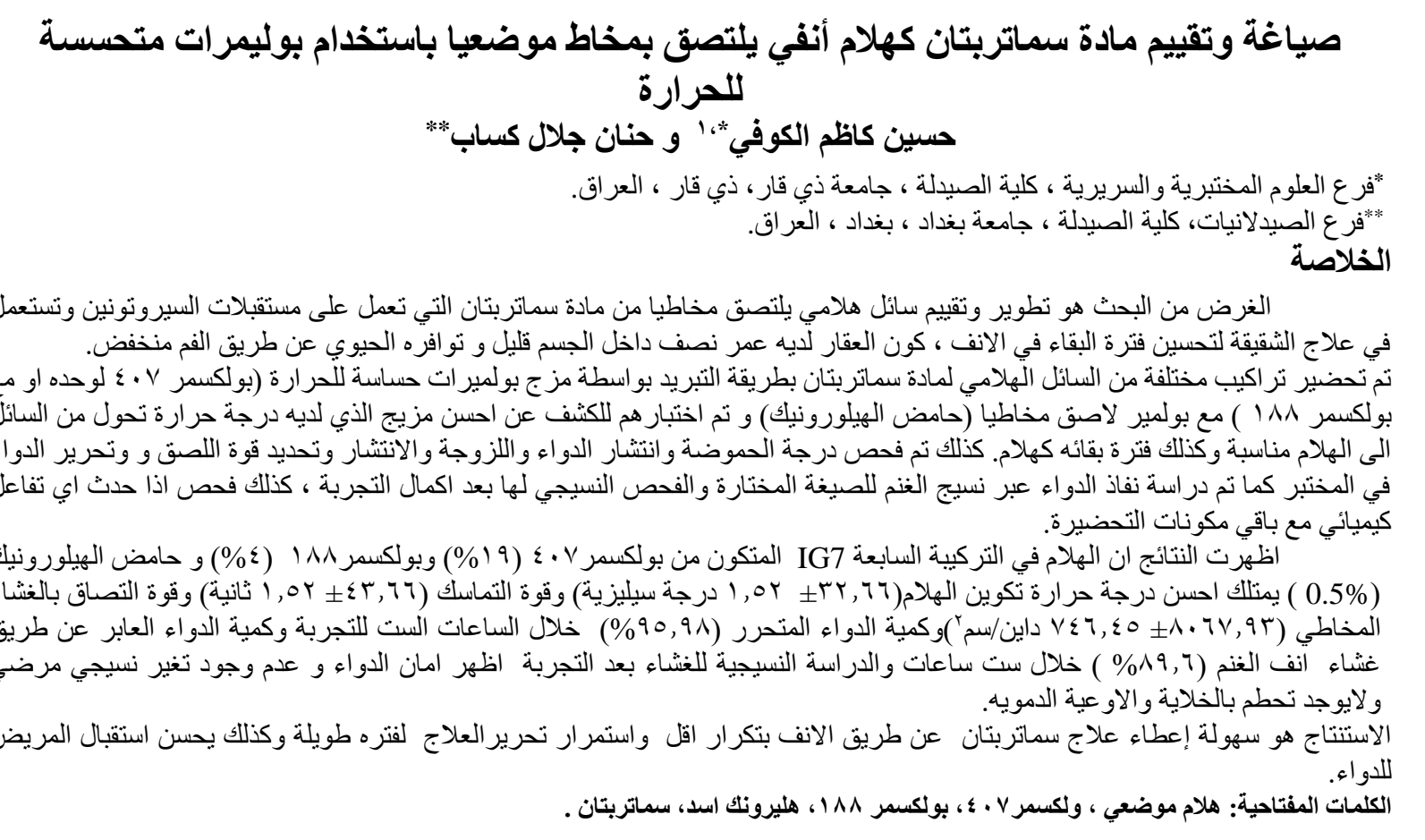

${ }^{1}$ Corresponding author E-mail: Ph.hussein.alkufi@gmail.com

Received: 25/5/2019

Accepted:3/8 /2019

Iraqi Journal of Pharmaceutical Sciences 


\section{Introduction}

Drug delivery by nasal route is one of the challenging endeavors facing the pharmaceutical technologist today. From the pharmacokinetic standpoint, intranasal administration of drug avoids first-pass metabolism and prevents incomplete absorption in the gastrointestinal tract which leads to improving the bioavailability ${ }^{(1)}$.

Therefore, approaches enhancing the nasal bioavailability is either by prolonging the contact time with the nasal surface via a viscosity-enhancing agent or in-situ gelling polymers or both approaches. An in-situ gel is a drug delivery system that exhibits sol-to-gel phase transition due to a change in specific physicochemical parameters such as ionic, temperature or $\mathrm{pH}^{(2)}$.

Thermoreversible polymers are substances having both solid and liquid-like properties which can be transported as a fluid and solidifies within the body temperature. The formulation has the advantage to stop the anterior leakage of the dosage form, reduce the taste impact and enhance the nasal bioavailability $^{(2)}$.

However, modern research turned extraordinary attention to hyaluronic acid (HA), a naturally occurring mucoadhesive polymer which, besides being biodegradable, showed to be highly biocompatible $^{(3)}$.

ST is a 5-HT1D and 5-HT1B (5hydroxytryptamine) receptor agonist used in the treatment of a cluster headache and migraine. Parental or oral routes are usually used to administer ST. However, a large proportion of patients suffer severe vomiting during their migraine attack, which may make oral management unacceptable.

ST has an oral bioavailability of $15 \%$; however, the problems associated with nasal delivery of ST solution is the low residence time in the nasal cavity (around 15minutes) resulting in low bioavailability, the remaining dose ST nasal solution is swallowed, and it arrives in the gastrointestinal tract where it is absorbed $^{(4,5)}$. The formulation of ST nasal in-situ gel using the thermosenstive polymer poloxamer and mucoadhesive polymer HA will enhance permeation and allow longer residence time and delay nasal clearance to avoid first pass metabolism, coupled with less frequent, ease of administration, is a promising dosage form to enhance patient compliance.

\section{Material}

ST, poloxamer407, poloxamer188 and HA was purchased from Hyperchem(China). Sodium chloride, calcium chloride and potassium chloride were purchased from Central Drug House, India. Benzalkonium chloride was provided by (Pioneer, Iraq). Substance and reagent used were all of analytical grade.

\section{Melting point determination and DSC}

The melting point was determined by using an open capillary tube technique as submitted by the United States Pharmacopeia (USP) ${ }^{(6)}$ and Differential scanning calorimetry (DSC) was used to evaluate the thermal behavior of pure drug using a DSC-60 (Shimadzu 60 plus Japan). A small amount of ST was closed in standard aluminum pans and then the temperature was raised from $50^{\circ} \mathrm{C}$ upto $300^{\circ} \mathrm{C}$ at a heating rate of $10^{\circ} \mathrm{C} / \mathrm{min}^{(7)}$.

\section{Preparation of nasal in situ gel containing $S T$}

Nasal IG of ST was prepared using the cold method. The cold method involved slow addition of poloxamer407 alone or with poloxamer 188 in cold water with continuous agitation. This dispersion was stored overnight at $4{ }^{\circ} \mathrm{C}$. The drug (ST $\left.5 \mathrm{mg} / \mathrm{ml}\right)$ and other additives (mucoadhesive polymer $\mathrm{HA}(0.5 \%$, $1.0 \%$ ), preservative (Benzylkonium chloride) were added to the poloxamer dispersion (Table 1) with continuous agitation in the next day. The formed mixtures were kept overnight at $4^{\circ} \mathrm{C}$. The nasal gel formulation having satisfactory gelation temperature $\left(30-37^{\circ} \mathrm{C}\right)$ was selected as optimized formulation $^{(8)}$.

Table1. Composition of ST nasal thermosensitive gel formulas

\begin{tabular}{||c|c|c|c|c|c|c||}
\hline \hline Formula No. & $\begin{array}{c}\text { Drug } \\
\mathrm{mg}\end{array}$ & $\begin{array}{c}\text { Poloxamer407 } \\
(\% \mathrm{w} / \mathrm{v})\end{array}$ & $\begin{array}{c}\text { Poloxamer } \\
188 \\
(\% \mathrm{w} / \mathrm{v})\end{array}$ & $\begin{array}{c}\text { HA } \\
(\% \mathrm{w} / \mathrm{v})\end{array}$ & $\begin{array}{c}\text { Benzylkonium } \\
\text { chloride } \\
(\% \mathrm{w} / \mathrm{v})\end{array}$ & $\begin{array}{c}\text { DW } \\
\mathrm{ml}\end{array}$ \\
\hline IG1 & 50 & 16 & ---- & 0.5 & 0.01 & 10 \\
\hline IG2 & 50 & 16 & ---- & 1 & 0.01 & 10 \\
\hline IG3 & 50 & 19 & ---- & 0.5 & 0.01 & 10 \\
\hline IG4 & 50 & 19 & ---- & 1 & 0.01 & 10 \\
\hline IG5 & 50 & 16 & 4 & 0.5 & 0.01 & 10 \\
\hline IG6 & 50 & 16 & 4 & 1 & 0.01 & 10 \\
\hline IG7 & 50 & 19 & 4 & 0.5 & 0.01 & 10 \\
\hline IG8 & 50 & 19 & 4 & 1 & 0.01 & 10 \\
\hline
\end{tabular}




\section{Gelation temperature}

Gelation temperature is the temperature at which the liquid phase makes a transition to gel. A gelation temperature range suitable for nasal IG formulation would be $32-34^{\circ} \mathrm{C}$. If the gelation temperature is lower than $32^{\circ} \mathrm{C}$, gelation occurs at room temperature leading to difficulty in manufacturing, handling and administering. If the gelation temperature is higher than $34^{\circ} \mathrm{C}$, the formulation will stay as a liquid at body temperature, resulting in nasal drainage ${ }^{(9)}$. The gelation temperature was determined by placing $2 \mathrm{ml}$ of the refrigerated formula(IG1-IG8) in a $10 \mathrm{ml}$ test tube with a diameter $1.0 \mathrm{~cm}$ and closed using parafilm. The tube was placed in a water bath at a temperature of about $4^{\circ} \mathrm{C}$. The water bath temperature was incremented slowly $\left(3^{\circ} \mathrm{C}\right)$ at the beginning of the experiment, and then $1^{\circ} \mathrm{C}$ when the temperature reached the region of the sol-gel transition temperature, and equilibration was allowed for 10 min after each temperature increment until gelation occurred. The test tube was tilted $90^{\circ}$, to confirm gelation has occurred, and the meniscus of the preparation did not move during slanting, this was recorded as the gelation temperature ${ }^{(10)}$.

\section{Gelation time}

Accurately $5 \mathrm{ml}$ of the prepared IG formulas (IG1-IG8) was added to $50 \mathrm{ml}$ of simulated nasal fluid(SNF) at $34 \pm 2^{\circ} \mathrm{C}$ in a beaker with mild stirring $(50 \mathrm{rpm})$ to avoid breaking of formed IG. $\mathrm{SNF}$ (pH 6.5) is composed of $7.45 \mathrm{mg} / \mathrm{ml}, \mathrm{NaCl}$ $1.29 \mathrm{mg} / \mathrm{ml}, \mathrm{KCl}$ and $0.32 \mathrm{mg} / \mathrm{ml}, \mathrm{CaCl}_{2} .2 \mathrm{H}_{2} \mathrm{O}$ prepared under continuous shaking for $24 \mathrm{~h}$ in a thermo-stated shaking water bath maintained at 37 ${ }^{\circ} \mathrm{C}^{(11)}$

Gelation time was observed visually by qualitative measurement and reported in terms of strokes and calibrated in three groups depending on gel stiffness, gelation time and duration

- (+)gelation happens after few minutes, stays for a few minutes and rapidly dispersed

- (++) gelation happens, immediately and continues for a few hours,

- (+++) gelation happens, immediately and continues for an extended period ${ }^{(12)}$.

\section{Drug content}

Accurately, $1 \mathrm{ml}$ of the formulation was diluted to $10 \mathrm{ml}$ with $\mathrm{SNF}$, and then $1 \mathrm{ml}$ of this solution was again diluted to $10 \mathrm{ml}$ with SNF.

Finally, the absorbance of the prepared solution was measured at $282 \mathrm{~nm}$ using UV visible Spectrophotometer ( EMC LAB-Germany) ${ }^{(7)}$. The samples were taken from three different regions of the gel from the upper, middle and bottom of the IG, and the mean drug content was measured.

\section{pH measurement}

The $\mathrm{pH}$ of nasal preparation is essential, mainly to prevent the growth of pathogenic bacteria, to avoid irritation of the nasal mucosa and to sustain normal physiological ciliary movement ${ }^{(13)}$. The $\mathrm{pH}$ of the prepared IG formulas (IG1, IG2, IG7, IG8) was measured at room temperature using $\mathrm{pH}$ meter ( Hanna-Italy) .

\section{Mucoadhesive force determination}

Mucoadhesive force is the power of adhesion of the formula to the nasal mucosa. The modified balance technique was used with a beaker at one side of the balance, and on the other side, a vial was fitted with sheep nasal mucosa (with a thickness of $0.6 \mathrm{~mm}$ cut from the sheep nose mucosa obtained from slaughtered sheep). The nasal mucosa was fitted on the bottom of the vial, as shown in figure 1 . The vials were kept at $32-34^{\circ} \mathrm{C}$ for $10 \mathrm{~min}$. Then $1 \mathrm{ml}$ of the gel sample was placed in a watch glass underneath the vial fitted with the nasal tissue. The vial was pressed down to the gel sample for one min as initial contact time. Then water was added to the beaker slowly on the other side of the balance using a pipette ${ }^{(14)}$.

The mucoadhesive force was calculated by determining the weight of water required to separate the mucosa from the gel by equation (1) :

$$
\text { Detachment force }\left(\frac{\text { dyne }}{\mathrm{cm}^{2}}\right)=\frac{m \times g}{A} \quad \text { Eq.(1) }
$$

Where; $\mathrm{m}$ is the required weight ( $\mathrm{g}$ ) for detachment, $\mathrm{g}$ is the acceleration $\left(980 \mathrm{~cm} / \mathrm{s}^{2}\right)$ due to gravity, and $\mathrm{A}$ is the exposed tissue area which is $3.14 \mathrm{~cm}^{2}$ in all preparations $^{(15)}$.

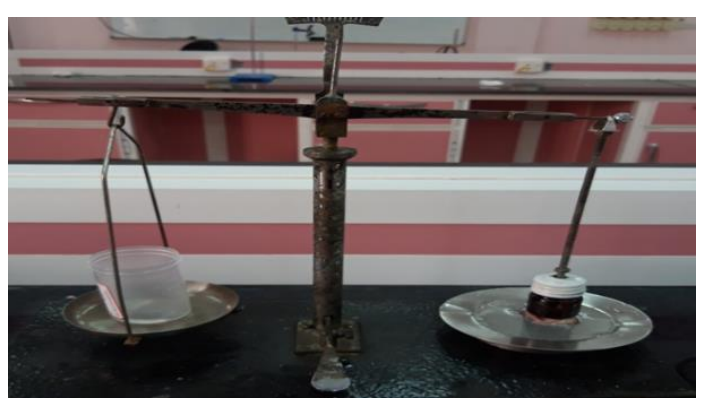

Figure 1. Modified mucoadhesive force measuring balance

\section{Gel strength}

A sample of $5 \mathrm{~g}$ of the gel was put in a $10 \mathrm{ml}$ graduated cylinder and placed in a thermostatically controlled water bath at $37^{\circ} \mathrm{C}$ for 30 minutes for gelation of the formulas. A mass of $3.5 \mathrm{~g}$ was placed on the surface of the gel. The gel strength was determined by the time in seconds required by the weight to penetrate $0.5 \mathrm{~cm}$ deep into the gel ${ }^{(16)}$.

\section{Spreadability test}

The spreadability of the IG formulas (IG1, IG2, IG7, IG8) was determined by placing approximately $1 \mathrm{~g}$ of the IG formula after complete gelation at a glass plate center (square area = $400 \mathrm{~cm}^{2}$ ). Another glass plate (same size) was used to cover the glass plate containing IG formula. The 
initial diameter of the IG was marked. Then, $1 \mathrm{k}$ scale weight was gently placed on the plate upper side for one min; as a consequence, the IG expand out in between the plates. Then the final diameter was marked after removal of the weight and the spreadability was measured in $\mathrm{cm}^{(17)}$.

Viscosity

The viscosity measurements were carried out by (digital viscometer NDJ-5S model, spindle $4)$. The viscosity measurements were performed at $34 \pm 1{ }^{\circ} \mathrm{C}$ to ensure gelation of the formulas. The gel was allowed to rotate for $1 \mathrm{~min}$ before viscosity measurement. The temperature detecting probe was lowered in the gel, and the temperature of the gel was recorded $^{(7)}$.

In-vitro release study of ST in-situ nasal gel

In-vitro drug release from the gel was determined for (IG1, IG2, IG7, IG8) by using a thermoregulated Franz diffusion cell system(Copley-USA), against control $(5 \mathrm{mg} / \mathrm{ml} \mathrm{ST}$ aqueous solution ) fitted with artificial dialysis membrane (MWCO 1200-1400 kDa) that was soaked in the receptor medium for $2 \mathrm{~h}$ before use. SNF (12 ml) pH6.5 was added into the receptor chamber maintained at $34 \pm 1{ }^{\circ} \mathrm{C}$. Gel with weight equivalent to $5 \mathrm{mg}$ of $\mathrm{ST}$ was placed into the donor compartment, and the whole setup was kept on stirring option. Aliquots of $1 \mathrm{ml}$ were removed at predetermined time intervals from the receptor compartment and replaced with fresh SNF, for $6 \mathrm{~h}$. The samples were diluted with $10 \mathrm{ml} \mathrm{SNF}$ and analyzed spectrophotometrically at $282 \mathrm{~nm}$, and the amount of the drug released was determined and the study is repeated in triplicate. Release kinetics was studied for the selected formula by using DD solver software $^{(9,18)}$.

\section{Ex vivo permeation study}

The ex vivo permeation studied was conducted using sheep nasal mucosal membrane. The sheep nasal mucosal membrane was mounted in between the donor and the receptor compartment of the diffusion cell (Copley-USA). Formulation equivalent to $5 \mathrm{mg}$ of drug was placed in the donor compartment which was in connection with the mucosal surface of the membrane, while the receptor compartment was filled with $12 \mathrm{ml}$ of SNF and its temperature was maintained at $34 \pm 1^{\circ} \mathrm{C}$. The content of the receptor compartment was continueously stirred by magnetic stirrer. A portion of $1 \mathrm{ml}$ was withdrawn from the receptor compartment at suitable time intervals and replaced with a similar volume of fresh SNF. The samples were diluted with $10 \mathrm{ml} \mathrm{SNF}$ and analyzed spectrophotometrically at $282 \mathrm{~nm}$ and the amount of the drug released was determined and the release was repeated in triplicate ${ }^{(7,9)}$.

Permeability coefficient $(\mathrm{cm} / \mathrm{s})$ of the drug was calculated by using the equation 2 ,

Permeability coefficient $=$
$(D C / D T) S S \times \frac{V}{A \times C D} \quad \mathbf{E q}(2)$

Where $(\mathrm{dc} / \mathrm{dt}) \quad \mathrm{ss}\left(\mu \mathrm{g} \quad \mathrm{mL}^{-1} \mathrm{~s}^{-1}\right)$ alteration of concentration under steady-state; $A$ is the permeation area equal $\left(3.14 \mathrm{~cm}^{2}\right)$; $\mathrm{v}(\mathrm{mL})$ the volume of the receiver section; and $\mathrm{CD}\left(\mu \mathrm{g} \mathrm{mL}{ }^{-1}\right)$ is the original donor concentration ${ }^{(9)}$.

\section{Histopathological studies}

After ex-vivo permeation study with ST nasal gel formulation, the histopathological evaluation of the nasal mucosal tissue was compared with control mucosal tissue incubated in the permeation chamber of Franz cell. Both tissues were fixed in $10 \%$ formalin, routinely processed, and embedded in paraffin. Paraffin sections were cut on glass slides and stained with hematoxylin and eosin to examine the morphological changes to the tissue via blinded study ${ }^{(19)}$.

\section{Compatibility studies by (FTIR)}

The FTIR spectrum of ST was recorded using a FTIR spectrometer (Biotech Engineering Management, UK) in a spectral region between 4000 and $400 \mathrm{~cm}^{-1}$ and analyzed by transmittance technique.

Compatibility studies were carried out at room temperature by FTIR to investigate any interactions between the drug and the excipients used in the formulation. The polymers were subjected to FTIR studies alone and in combinations with the $\operatorname{drug}^{(20)}$.

\section{Statistical analysis}

The results of the experiments were given as mean values \pm standard deviation (SD) and analyzed according to the one-way analysis of variance (ANOVA) at which significant results $(\mathrm{p}<0.05)$ and non-significant ( $\mathrm{p}>0.05)$.

\section{Results and Discussion Melting point and DSC}

The measured melting point of ST by using the capillary method was found to be $169^{\circ} \mathrm{C}$, which is consistent with the reported melting point range $\left(168-172^{\circ} \mathrm{C}\right)^{(21)}$, which indicates the purity of drug powder.

The differential scanning calorimetry of pure ST powder is shown in figure 2 and complied with reference ${ }^{(21)}$. The DSC thermogram of the real drug showed an endothermic peak of $172^{\circ} \mathrm{C}$, corresponding to the melting point of the crystalline form of the $\operatorname{drug}^{(21)}$. 


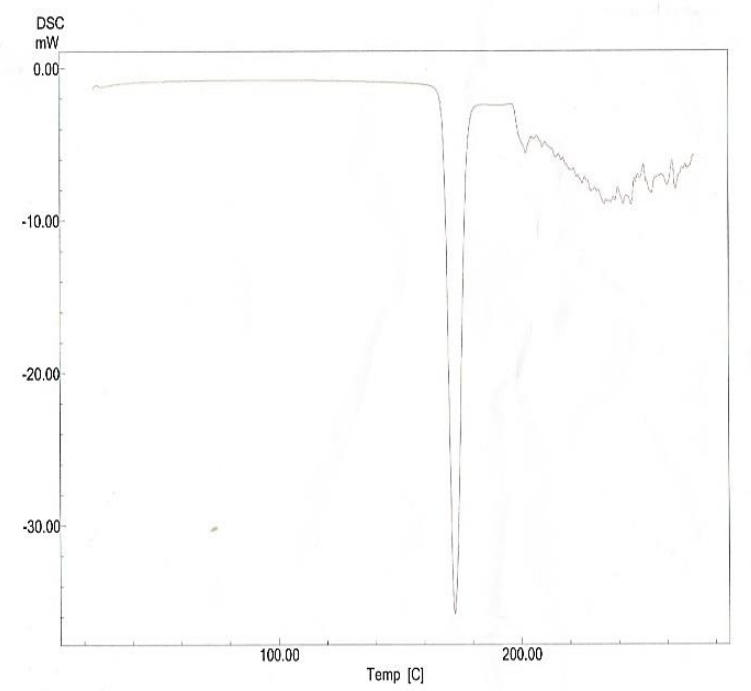

Figure 2. Differential scanning calorimetry thermogram of ST.

\section{Gelation temperature}

Poloxamer 407 and poloxamer188 were selected due to their thermosensitive gelling properties. Also, Poloxamer 407 and Poloxamer188 were known to have low toxicity, low irritation, excellent water solubility, excellent drug release characteristics and compatibility with a wide range of excipients. Poloxamer407 or poloxamer 188 alone could not provide a suitable gelation temperature because at higher concentrations of poloxamer407, the larger ratio of polypropylene oxide (PPO) causes dehydration and aggregation at a lower temperature leading the micelles to become more entangled and greater ease of gelation at lower temperature. Concomitantly, the addition of poloxamer188 increases the ratio of polyethylene oxide (PEO) leading the micelles to become less entangled there by raising the critical micelle temperature (CMT) ${ }^{(22)}$. In cases of mixtures of poloxamer407 and poloxamer188, several formulations gelled at the body temperature. As the concentration of poloxamer407 increased, the mixtures needed smaller amounts of poloxamer188 to gel at the desired gelation temperature. The formulas with percentage $(\mathrm{w} / \mathrm{w})$ ratios of poloxamer 407/poloxamer188 with suitable gelation temperature of $32-34^{\circ} \mathrm{C}$ (Table 2) are used for further study ${ }^{(23)}$.

\section{Gelation time}

The gelation study was conducted in $\mathrm{SNF}(\mathrm{pH}$ 6.5). All the formulations on contact with the gelation medium had undergone sol-to-gel transition due to the presence of gel-forming polymers such as poloxamer and HA. Gelation characteristics of the formulations showed that increasing the concentration of poloxamer 407 increased the gelation time, while the combination with poloxamer 188 showed less gelation time as seen in (Table 2). Also the rise in the concentration of HA increased the time of gelation for the formulas.

Table 2. Gelation temperature and gelation time of IG formulas

\begin{tabular}{|l|c|c|}
\hline $\begin{array}{l}\text { Formula } \\
\text { no. }\end{array}$ & $\begin{array}{c}\text { Gelation temp } \\
\text { Mean } \pm \text { SD } \\
\mathrm{n}=3\end{array}$ & Gelation time \\
\hline IG1 & $30.16 \pm 0.76$ & ++ \\
\hline IG2 & $27.33 \pm 0.76$ & +++ \\
\hline IG3 & $26.33 \pm 1.15$ & ++ \\
\hline IG4 & $24.16 \pm 0.76$ & +++ \\
\hline IG5 & $43.00 \pm 1.00$ & + \\
\hline IG6 & $38.66 \pm 1.52$ & + \\
\hline IG7 & $32.66 \pm 1.52$ & ++ \\
\hline IG8 & $29.33 \pm 1.04$ & +++ \\
\hline
\end{tabular}

\section{Drug content}

The drug content was found to be in the acceptable range of all the formulations. This indicates that the process employed in this study was capable of producing gels with uniform drug content and minimal variability, as seen in table 3 .

\section{pH determination}

The $\mathrm{pH}$ of the formulations was established to be acceptable ${ }^{(13)}$ and was in the range of 4.5-6.5, as shown in table 3 .

Table 3. ST intranasal gel drug content and $\mathbf{p H}$ of the formulas

\begin{tabular}{||c|c|c||}
\hline $\begin{array}{c}\text { Formula } \\
\text { No. }\end{array}$ & $\begin{array}{c}\text { Drug content } \\
\text { Mean } \pm \text { SD } \\
\mathrm{n}=3\end{array}$ & $\begin{array}{c}\mathrm{pH} \\
\text { Mean } \pm \text { SD } \\
\mathrm{n}=3\end{array}$ \\
\hline IG1 & $99.93 \pm 0.01$ & $5.66 \pm 0.05$ \\
\hline IG2 & $99.27 \pm 0.06$ & $5.56 \pm 0.05$ \\
\hline IG7 & $99.98 \pm 0.02$ & $6.10 \pm 0.10$ \\
\hline IG8 & $99.91 \pm 0.03$ & $6.33 \pm 0.05$ \\
\hline
\end{tabular}

\section{Determination of mucoadhesive strength}

In the study, the formulations prepared with the high concentration of HA exhibited more mucoadhesion strength due to the ability of HA to comprise hydrogen bonding, high molecular weight and the semi-flexible chain. The bioadhesive bond between the formulation and mucin dispersion became stronger at temperature range $32-34^{\circ} \mathrm{C}$ due to formation of more compact lattice structure as well as increase of density ${ }^{(24)}$, as shown in table 4. 
Table 4. Detachment weight(G) and mucoadhesive force per squre root of area $\left(d y n e / \mathrm{cm}^{2}\right)$ of IG formulas.

\begin{tabular}{||c|c|c||}
\hline $\begin{array}{c}\text { Formula } \\
\text { No. }\end{array}$ & $\begin{array}{c}\text { Detachment } \\
\text { weight } \\
(\mathrm{g}) \\
\text { Mean } \pm \text { SD } \\
\mathrm{n}=3\end{array}$ & $\begin{array}{c}\text { Mucoadhesive } \\
\text { force } \\
\left(\mathrm{dyne} / \mathrm{cm}^{2}\right) \\
\text { Mean } \pm \text { SD } \\
\mathrm{n}=3\end{array}$ \\
\hline IG1 & $20.33 \pm 2.51$ & $6345.03 \pm 785.43$ \\
\hline IG2 & $26.66 \pm 1.52$ & $8320.63 \pm 476.74$ \\
\hline IG7 & $25.85 \pm 1.52$ & $8067.83 \pm 746.45$ \\
\hline IG8 & $30.00 \pm 1.00$ & $9363.05 \pm 312.10$ \\
\hline
\end{tabular}

Gel strength and spreadability

The formulations showed good gel strength (Table 5) which ranged from the low as $(38.33 \pm 2.08 \mathrm{~s})$ for IG5 to the higher value of $(51.33 \pm 3.21 \mathrm{~s})$ for IG8, the combination of poloxamer and HA gave strength to the formula. Gel strength indicates the tensile strength of the gelled mass. It demonstrates the ability of the gelled mass to resist the ciliary movement in vivo ${ }^{(25)}$.

The gel strength of nasal gel formulation at $34^{\circ} \mathrm{C}$, increased as the concentration of $\mathrm{HA}$ and poloxamer concentration increased. The mechanism of the increase gel strength might be related to hydrogen bonding between poloxamer and bioadhesive polymers in the nasal gel ${ }^{(8)}$.

Table 5. Gel strength and spreadability of IG formulas.

\begin{tabular}{|c|c|c|}
\hline $\begin{array}{c}\text { Formula } \\
\text { No. }\end{array}$ & $\begin{array}{c}\text { Gel strength } \\
(\mathrm{sec}) \\
\text { Mean } \pm \text { SD } \\
\mathrm{n}=3\end{array}$ & $\begin{array}{c}\text { Spreadability } \\
(\mathrm{cm}) \\
\text { Mean } \pm \text { SD } \\
\mathrm{n}=3\end{array}$ \\
\hline IG1 & $38.33 \pm 2.08$ & $5.03 \pm 0.15$ \\
\hline IG2 & $45.33 \pm 1.52$ & $3.56 \pm 0.49$ \\
\hline IG7 & $43.66 \pm 1.52$ & $4.06 \pm 0.11$ \\
\hline IG8 & $51.33 \pm 3.21$ & $2.93 \pm 0.15$ \\
\hline
\end{tabular}

By evaluating the spreadability of the nasal IG of ST, it was observed that as the concentration of polymers used (combination of poloxamer 407 and188) increased the spreadability decreased. The values indicate that the nasal IG has excellent spreadability according to acceptable range (2.5$7 \mathrm{~cm}$ ), which is desired for the application of the nasal $\mathrm{IG}^{(26)}$, as shown in table 5.

\section{Viscosity measurements}

The viscosity of selected IG formulations determined at $6,12,30,60 \mathrm{rpm}$ at $34 \pm 1^{\circ} \mathrm{C}$. The results of the viscosity measurement of IG7, IG8 are shown in table 6. The increase in viscosity of the formulations was observed with the increase in the concentration of HA polymer which could be related to the increasing polymer chain entanglement and higher chance of hydrogen bonding at higher concentration of the polymer ${ }^{(25)}$. IG8 is very viscous, making it very difficult to pour from the container

Table6.Viscosities of IG7 and IG8 at their gelation temperature $34 \pm 1^{\circ} \mathrm{C}, \pm \mathrm{SD}$

\begin{tabular}{||c|c|c|c|c||}
\hline \multirow{4}{*}{$\begin{array}{r}\text { Rotation } \\
\text { speed } \\
\text { rpm }\end{array}$} & \multicolumn{4}{|c||}{ Viscosity(cP) } \\
\cline { 2 - 5 } & $6 \mathrm{rpm}$ & $12 \mathrm{rpm}$ & 30rpm & $60 \mathrm{rpm}$ \\
& Mean & Mean $\pm \mathrm{S}$ & Mean & Mean \\
& $\pm \mathrm{SD}$ & $\mathrm{D}$ & $\pm \mathrm{SD}$ & $\pm \mathrm{SD}$ \\
Formula & $\mathrm{n}=3$ & $\mathrm{n}=3$ & $\mathrm{n}=3$ & $\mathrm{n}=3$ \\
\hline IG7 & 1821.00 & 1624.66 & 1189.66 & 850.00 \\
& \pm 18.24 & \pm 22.47 & \pm 9.50 & \pm 20.00 \\
\hline IG8 & 3013.33 & 2533.33 & $1826.66 \pm$ & 1283.0 \\
& \pm 15.27 & \pm 15.27 & 15.27 & \pm 20.66 \\
\hline
\end{tabular}

In-vitro release study of ST in-situ nasal gel

In vitro drug release of IG7 showed drug release $95.98 \%$ after $6 \mathrm{~h}$ in Franz diffusion cell. It was found that as the concentration of polymers increased (poloxamer and HA) a decrease in the drug release was obtained, as shown in figure 3 . It was obvious that the release of ST was not only affected by poloxamer concentration but by the mucoadhesive polymer HA. The mucoadhesive polymer retarded the drug release from nasal gel due to high gel viscosity and squeezed aqueous channels by which the drug is distributed between the poloxamer micelles ${ }^{(8)}$.

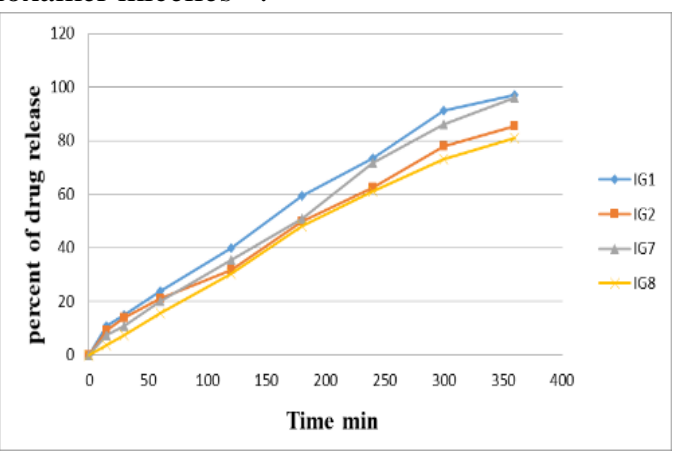

Figure 3. In vitro release profile for IG1, IG2, IG7 and IG8 in SNF at $34 \pm 1^{\circ} \mathrm{C}$.

The percentage of ST released from the control (ST aqueous solution) was compared with that from nasal in-situ gelling using the dialysis membrane. Faster release of ST solution in comparism to IG 7 was obtained with a significant difference $(p<0.05)$. The percent of drug release from the ST solution is $99.33 \%$ in $2 \mathrm{~h}$ while the percent of drug release from IG7 in 6h was $95.89 \%$ as shown in the figure 4 , due to the presence of polymers. 


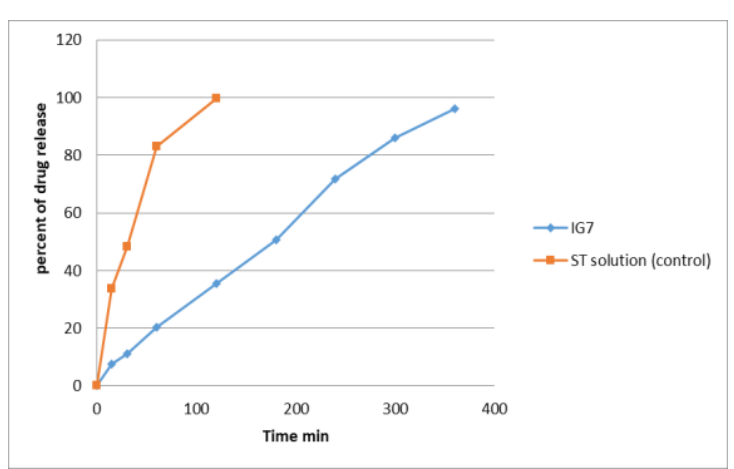

Figure 4. In vitro release profile of IG7 in comparison with ST solution (control) in SNF at $34 \pm 1^{\circ} \mathrm{C}$.

\section{Ex-vivo permeation study}

Ex-vivo permeation profile of IG7 is shown in figure 5. Sustained release was obtained from IG7 since it released about $89.6 \%$ through nasal mucosa of sheep within $6 \mathrm{~h}$, which is considered optimal since the ST half life is $2 \mathrm{~h}^{(21)}$, so the formulation will sustain the release for three half lives.

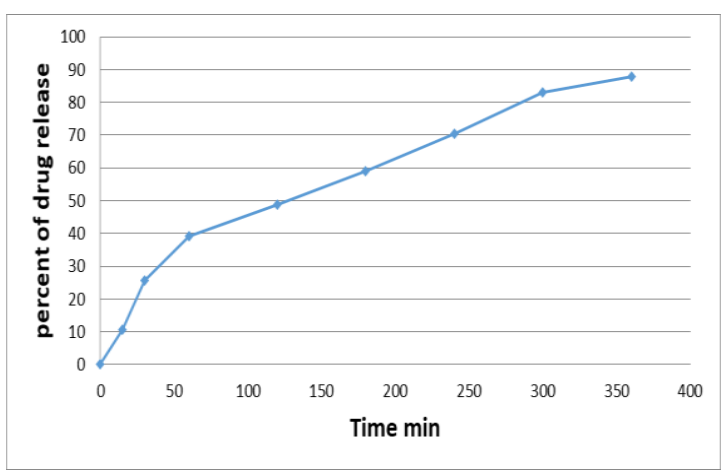

Figure 5. Percentage cumulative permeation of drug from IG7 through the nasal mucosa in SNF at $34 \pm 1^{\circ} \mathrm{C}$.

Permeability co-efficient of ST at $4 \mathrm{~h}$ for IG7 were found to be $1.44 \times 10^{-5} \mathrm{~cm} / \mathrm{s}$. Nasal IG7 showed the initial high flux value as $48.54 \times 10^{-4} \mu \mathrm{g} \mathrm{ml}^{-1} \mathrm{~s}^{-1}$. A decrease in the value of flux was observed at 2,3 and $4 \mathrm{hrs}$ resulting in flux value of $8.27,17.69$ and $18.94\left(10^{-4} \mu \mathrm{g} \mathrm{ml}^{-1} \mathrm{~s}^{-1}\right)$ respectively. Initial rapid release may be due to the exposure of fresh surface of drug present in gel to the sheep mucosa and sustained drug release after $1 \mathrm{~h}$ may be due to the polymers like poloxamer407 which slightly decrease the rate of drug release due to enhanced micellar structure and gel network ${ }^{(9)}$ and the presence of HA (hydrophilic polymer) which entrap the drug and sustain the release.

The release data of the gel formulation (Table 7) were kinetically analyzed by different mathematic models like zero order, first order, Higuchi and Korsmeyer-Peppas ( for $60 \%$ release). the good fitness was represented by $\mathrm{R}^{2}$. Formula IG7 best fit to zero order model because it has the highest $\mathrm{R}^{2}$ values.

From Korsmeyer-Peppas equation, the $\mathrm{n}$ value was between 0.45 and 0.89 , which indicates anomalous or non-Fickian release. Suggesting that the release was controlled by the diffusion rate (zero order mode ) and the relaxation rate of the hyaluronic acid polymer matrix ${ }^{(9,27)}$.

Table7. Model fitting for IG7 formulation.

\begin{tabular}{||l|c|c||}
\hline \multirow{2}{*}{ Models } & \multicolumn{2}{|c||}{ Formulation } \\
\cline { 2 - 3 } & $\begin{array}{c}\text { In Vitro drug } \\
\text { release }\end{array}$ & $\begin{array}{c}\text { Ex-vivo drug } \\
\text { release }\end{array}$ \\
\hline $\begin{array}{l}\text { Zero } \\
\left.\text { order( } \mathrm{R}^{2}\right)\end{array}$ & 0.99 & 0.98 \\
\hline $\begin{array}{l}\text { First } \\
\left.\text { order( } \mathrm{R}^{2}\right)\end{array}$ & 0.95 & 0.96 \\
\hline Higuchi( $\left.\mathrm{R}^{2}\right)$ & 0.90 & 0.92 \\
\hline $\begin{array}{l}\text { Korsmeyer } \\
\text { peppas }\left(\mathrm{R}^{2}\right) \\
\mathrm{n} \text { value }\end{array}$ & $\begin{array}{c}0.99 \\
\mathrm{n}=0.82\end{array}$ & $\begin{array}{c}0.98 \\
\mathrm{n}=0.79\end{array}$ \\
\hline
\end{tabular}

\section{Histopathological studies}

Safety is an essential concern for the administration of the formulation. Hence, it was essential to investigate the safety of the optimized in situ gel formulation (IG7). Thus, it was essential to study the histology of the nasal mucosa with the formulation. The histology of control nasal mucosa (without treatment) and treated nasal mucosa is shown in figure 6 . The microscopic observations indicated that the formulation had no significant effect on the microscopic structure of the sheep nasal mucosa. The surface epithelium lining and the granular cellular structure of the nasal mucosa were totally intact. Thus the histological study revealed the safety of ST in situ nasal gel formulation on the sheep nasal mucosa. 


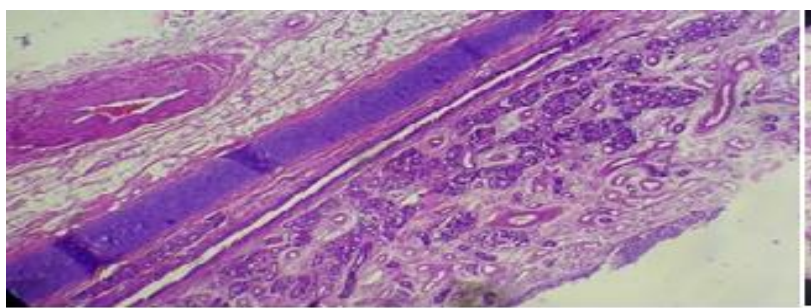

A

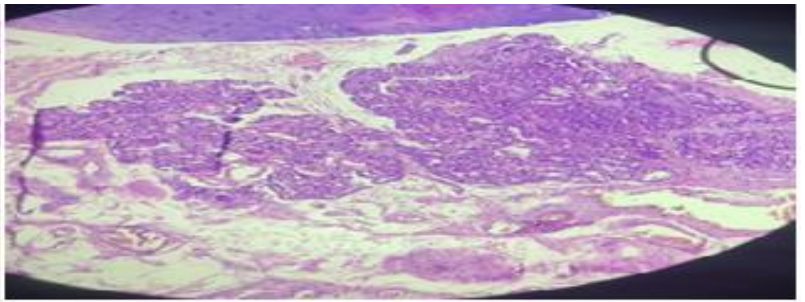

B

Figure 6. Histopathological evaluation of sections of sheep nasal mucosa. A. Mucosal tissue incubated in SNF (pH 6.5), B. Mucosal tissue incubated in the permeation chamber with IG7 formulation.

\section{Compatibility studies by FTIR}

The FTIR spectrum of ST powder is shown in figure 7 and is in agreement with previous reported study ${ }^{(28)}$. It was found that the characteristic peaks of ST at $3367.71 \mathrm{~cm}^{-1}, 1234.44 \mathrm{~cm}^{-1}, 632.65 \mathrm{~cm}^{-}$ ${ }^{1}, 1342.46 \mathrm{~cm}^{-1}$ and $1138 \mathrm{~cm}^{-1}$ corresponding to the $\mathrm{NH}$ stretching, C-N stretching, C-S stretching and $\mathrm{S}=\mathrm{O}$ (sulfones) stretching respectively.

The FTIR spectrum of the selected formula of IG7 showed small shifting in the chief characteristic bands of the drug in IG7 in comparison with the bands of the pure drug, indicating no interaction between drug and other additives used in IG7 formulation.

FTIR spectrum for poloxamer407 and poloxamer188 showed bands at $3483.44 \mathrm{~cm}^{-1}$, $2881.65 \mathrm{~cm}^{-1}, \quad 1280.73 \mathrm{~cm}^{-1}$ for $\mathrm{O}-\mathrm{H}$ stretching, aliphatic $\mathrm{C}-\mathrm{H}$ stretching and $\mathrm{C}-\mathrm{O}$ stretching in C-O$\mathrm{C}$ group respectively. Characteristics peaks of $\mathrm{ST}$ in IG7 were found for $\mathrm{N}-\mathrm{H}$ str. at $3363.86 \mathrm{~cm}^{-1}, \mathrm{C}-\mathrm{N}$ str. at $1203.58 \mathrm{~cm}^{-1}, \mathrm{~S}=\mathrm{O}$ str. at $1342.46 \mathrm{~cm}^{-1}$ and $1138 \mathrm{~cm}^{-1}$, C-S str. at $632.65 \mathrm{~cm}^{-1(7,8)}$.

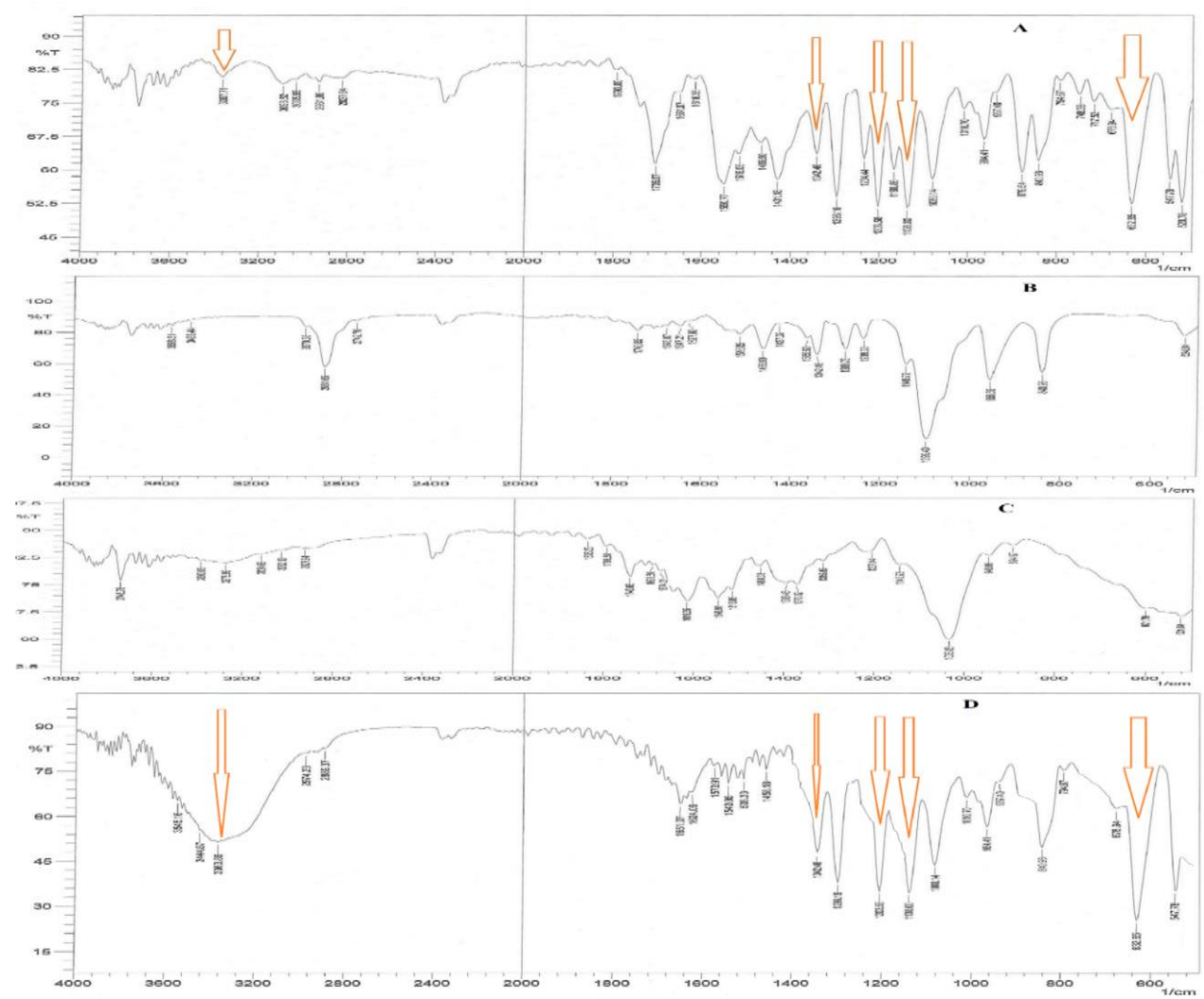

Figure (7) Compatibility FTIR, A: sumatriptan B: poloxamer407 and poloxamer188, C: HA, D: IG7 


\section{Conclusion}

Based on the results obtained from this study, it can be concluded that ST intranasal In-situ gel was successfully prepared using poloxamer 407 and poloxamer 188 .

All the formulations were found to have the desired amount of drug content. Addition of mucoadhesive polymers to the formulas increased the viscosity and thereby increased mucoadhesive strength of the formed gel. The optimized formula IG7 (poloxamer 407 19\%, poloxamer 188 4\%, HA $0.5 \%$ ) showed drug release of $95.98 \%$ within $6 \mathrm{~h}$. Exvivo studies on sheep olfactory nasal mucosa showed permeation of $89.6 \%$ within $6 \mathrm{~h}$. IG7 formulation exhibited diffusion release kinetics (zero order model). The release profile of ST showed both diffusion and erosion mechanism, anomalous diffusion. The optimized formula IG7 was found to be safe since no histopathological changes were observed.

\section{References}

1. Jadhav KR, Gambhire MN, Shaikh IM, Kadam VJ, Pisal SS. Nasal drug delivery systemfactors affecting and applications. Curr Drug ther. 2007;2(1):27-38.

2. HB N, Bakliwal SR, Pawar SP. In-situ gel: new trends in controlled and sustained drug delivery system. 2010;2(2):1408-1398.

3. Mayol L, Quaglia F, Borzacchiello A, Ambrosio L, La Rotonda MI. A novel poloxamers/hyaluronic acid in situ forming hydrogel for drug delivery: rheological, mucoadhesive and in vitro release properties. Eur J Pharm Biopharm. 2008;70(1):199-206.

4. Ryan R, Elkind A, Baker CC, Mullican W, DeBussey S, Asgharnejad M. Sumatriptan nasal spray for the acute treatment of migraine: results of two clinical studies. Neurology. 1997;49(5):1225-30.

5. Majithiya RJ, Ghosh PK, Umrethia ML, Murthy RSR. Thermoreversible-mucoadhesive gel for nasal delivery of sumatriptan. AAPS pharmscitech. 2006;7(3):E80-6.

6. The United States Pharmacopoeia (USP) 36, USA. The United States Pharmacopeial Convention Inc. 2012.

7. Galgatte UC, Kumbhar AB, Chaudhari PD. Development of in situ gel for nasal delivery: design, optimization, in vitro and in vivo evaluation. Drug Deliv. 2014;21(1):62-73.

8. Godbole M, There PW, Dangre P. Formulation and optimization of prolonged release nasal in situ gel for treatment of migraine. Indo Am J Pharm Res. 2014;4:1320-32.

9. Shelke S, Shahi S, Jalalpure S, Dhamecha D, Shengule S. Formulation and evaluation of thermoreversible mucoadhesive in-situ gel for intranasal delivery of naratriptan hydrochloride. J Drug Deliv Sci Technol. 2015;29:238-44.
10. Allah AKA, Abd-Al Hammid SN. Preparation and evaluation of chloramphenicol as thermosensitive ocular in-situ gel. Iraqi J Pharm Sci. 2012;21(2):98-105.

11. Farid RM, Etman MA, Nada AH, Abd El Azeem RE. Formulation and in vitro evaluation of salbutamol sulphate in situ gelling nasal inserts. Aaps Pharmscitech. 2013;14(2):712-8.

12. Madan JR, Adokar BR, Dua K. Development and evaluation of in situ gel of pregabalin. Int $\mathbf{J}$ Pharm Investig. 2015;5(4):226.

13. Chand DR, Datta MS, Tilak Vijay K, Gupta Anish K. A review on factors affecting the design of nasal drug delivery system. Int J drug Deliv. 2011;3:194-208.

14. Gaikwad V. Formulation and evaluation of InSitu gel of metoprolol tartrate for nasal delivery. J Pharm Res. 2010;3(4):788-93.

15. Abdul BI, Rajab NA. Preparation and in-vitro evaluation of mucoadhesive clotrimazole vaginal hydrogel. Iraqi J Pharm Sci (P-ISSN 1683-3597, E-ISSN 2521-3512). 2014;23(1):19-25.

16. Al-Wiswasi NN, Al-Khedairy EBH. Formulation and in vitro Evaluation of In-situ Gelling Liquid Suppositories for Naproxen. Iraqi J Pharm Sci (P-ISSN 1683-3597, E-ISSN 2521-3512). 2008;17(1):31-8.

17. Garg A, Aggarwal D, Garg S, Singla AK. Spreading of semisolid formulations: an update. Pharm Technol North Am. 2002;26(9):84.

18. Basu S, Bandyopadhyay AK. Development and characterization of mucoadhesive in situ nasal gel of midazolam prepared with Ficus carica mucilage. Aaps Pharmscitech. 2010;11(3):1223-31.

19. Salunke SR, Patil SB. Ion activated in situ gel of gellan gum containing salbutamol sulphate for nasal administration. Int J Biol Macromol. 2016;87:41-7.

20. Pavia L L. Introduction to spectroscopy, $3^{\text {rd ed }}$, Harcourt college publishers, New Delhi; 2006. $353 \mathrm{p}$.

21. Moffat A. C., Osselton M. D., Widdop B. editors. Clarke's analysis of drugs and poisons. $3^{\text {rd ed }}$. Pharmaceutical Press; 2011. 2098 p.

22. Jeong B, Kim SW, Bae YH. Thermosensitive sol-gel reversible hydrogels. Adv Drug Deliv Rev. 2012;64:154-62.

23. Kute JU, Darekar AB, Saudagar RB. A Review: In-Situ Gel-Novel Approach for Nasal Delivery. World J Pharm Pharm Sci. 2013;3(1):187-203.

24. Cowman MK, Schmidt TA, Raghavan $P$, Stecco A. Viscoelastic properties of hyaluronan in physiological conditions. F1000Research. 2015;4. 
25. Sindhoor SM, Priya S, Maxwell A. Formulation and evaluation of novel in situ gel of lafutidine for gastroretentive drug delivery. Asian J Pharm Clin Res. 2018;11(8):88-94.

26. Chaudhary B, Verma S. Preparation and Evaluation of Novel In Situ Gels Containing Acyclovir for the Treatment of Oral Herpes Simplex Virus Infections. 2014;2014.
27. Ampati S, Hanumakonda A, Maheshwaram V. Formulation and evaluation of nasal in situ gel of fluoxetine hydrochloride. Indo Am J Pharm Sci. 2016;3(6):573-81.

28. Prajapati ST, Patel PB, Patel CN. Formulation and evaluation of sublingual tablets containing Sumatriptan succinate. Int J Pharm Investig. 2012;2(3):162. 